\title{
The effect of modified atmospheres on the rate of quality change in 'Hass' avocado
}

\author{
Maarten L.A.T.M. Hertog*, Sue E. Nicholson, Kerry Whitmore ${ }^{1}$ \\ Fresh Technologies, Institute of Food Nutrition and Human Health, Massey University, Private Bag 11 222, Palmerston North, \\ New Zealand
}

Received 17 June 2002; accepted 7 October 2002

\begin{abstract}
Gas exchange rates and quality changes of avocados (Persea americana, Mill., cv. 'Hass') stored at $7{ }^{\circ} \mathrm{C}$ in 32 different modified atmosphere (MA) conditions generated using a flow-through system, were monitored to characterise their functional relationship. An integrated modelling approach was used to link rates of quality loss to the rate of gas exchange. This revealed a close quantitative relationship between the gas exchange of 'Hass' avocado fruit on one hand and weight loss, colour change and softening on the other, indicating a direct metabolical link between these processes. High $\mathrm{CO}_{2}$ lowered the respiratory quotient of avocado, an effect which, based on literature, could be explained by a shift from oxidative phosphorylation into the alternative respiratory pathway. In the model approach, the rates of quality degrading processes were linked to oxidative phosphorylation only, assuming this is where ATP was being produced. At high $\mathrm{CO}_{2}$ levels at aerobic conditions, unaccounted weight loss data indicated a considerable volatile production which, however, was not qualitatively characterised. Both weight loss and colour change indicated the involvement of anaerobic processes at low $\mathrm{O}_{2}$ levels. At $2 \mathrm{kPa} \mathrm{O}_{2}$ and $0 \mathrm{kPa} \mathrm{CO} \mathrm{CO}_{2}$ no $\mathrm{CO}_{2}$ injury occurred, while the change in hue was minimal, weight loss was minimised, and softening was almost completely inhibited. At such low $\mathrm{O}_{2}$ levels, no additional benefit was found from raising the levels of $\mathrm{CO}_{2}$.
\end{abstract}

(C) 2002 Elsevier Science B.V. All rights reserved.

Keywords: Avocado; Colour; Firmness; Gas exchange; MA; Modelling; Persea americana; Quality; RQ; Weight loss

\footnotetext{
* Corresponding author. Present address: KULeuven Lab. Naoogsttechnologie, de Croylaan 42, B-3001 Heverlee, Belgium. Tel.: +32-16-322-376; fax: +32-16-322-955.

E-mail address: maarten.hertog@agr.kuleuven.ac.be (M.L.A.T.M. Hertog).

${ }^{1}$ Present address: Te Awamutu College, Te Awamutu, New Zealand
}

\section{Introduction}

It is generally accepted that modified atmospheres (MA) can inhibit the loss of quality during the postharvest life of a wide range of products (Kader et al., 1989). Although much research has been done to define optimum MA conditions for many fresh food products, the underlying mechanisms for the action of MA are still only superficially understood. Application of MA generally 
involves reducing oxygen levels $\left(\mathrm{O}_{2}\right)$ and elevating levels of carbon dioxide $\left(\mathrm{CO}_{2}\right)$, thus, reducing oxidative respiration. Parallel to the effect on respiration, the energy needed to support other metabolic processes is affected, as are, consequently, the processes themselves.

Quality attributes, such as texture, generally change with time, as part of the normal ripening metabolism of the product (Tijskens and Polderdijk, 1996). Those developmental changes directly influenced by $\mathrm{O}_{2}$ or $\mathrm{CO}_{2}$, or driven by the energy supplied by respiration or fermentation, would all be affected by applying MA conditions. Some of these processes are affected more than others because of the way they depend on atmospheric conditions (Kanellis et al., 1993). Besides inhibiting ripening through inhibition of ethylene production, MA also affects ripening through inhibition of ethylene action (Solomos and Kanellis, 1997). $\mathrm{O}_{2}$ requiring processes will be affected straight away through the availability of $\mathrm{O}_{2}$. Although much work has been done on showing the general effects of MA conditions, quantification of the effects on changes in quality attributes is still limited.

Such a relationship between rate of gas exchange and rate of quality loss has been seen in broccoli (Polderdijk et al., 1995), where the rate of discoloration of buds depended on atmospheric composition. Also, deterioration of asparagus spears appeared to be strongly related to its own metabolic rate (Brash et al., 1995). Tijskens (1996) suggested using metabolic rate as a rate index for quality changes and Hertog et al. (1999) applied this approach to explain the effects of MA on spoilage of strawberries.

To increase our understanding of the effect of MA on quality, we have been studying quality changes under MA conditions for a number of important New Zealand export crops. Earlier work on 'Braeburn' apples showed that softening and gas exchange had comparable $\mathrm{Km}$ values indicating a common kinetic background (Hertog et al., 2001). It also revealed a close quantitative relationship between rate of softening and rate of gas exchange of 'Braeburn' apples, indicating that fruit softening is metabolically linked to gas exchange.
The current paper presents results on avocado (Persea americana, Mill., cv. Hass). Although some work has been done on the effect of MA on quality changes in avocado fruit (Meir et al., 1995 , 1997) the two have not previously been linked together in a quantitative way. Although the relationship between gas exchange rates and rates of quality loss will be much more complex, and for climacteric fruit should take into account the involvement of ethylene, a first approach is taken by linking the rates of gas exchange directly to the rates of the main quality decay processes in avocado.

\section{Material and methods}

\subsection{Fruit}

Export quality 'Hass' avocados ( $P$. americana, Mill.) were obtained from one grower from the Auckland region, New Zealand. Fruit were harvested early February 2000 (for the MA experiment), or mid November 2000 (for the low $\mathrm{CO}_{2}$ treatments), graded, packed and couriered overnight to Massey University. On arrival, fruit were individually labelled, locations for colour and firmness measurements were marked with a circular stamp at both base and stem end, and initial fruit measurements were taken.

\section{2. $M A$}

Thirty-two PVC containers (volume $=0.0135$ $\mathrm{m}^{3}$ ) were packed on the same day with 19 fruit each (average fruit weight of $198 \mathrm{~g}$ ) and stored at an air temperature of $7{ }^{\circ} \mathrm{C}$, using a range of different MA. A separate sample of 30 fruit was stored in its original box in the same cold room for control measurements during the experiment. The main purpose of the air-stored control fruit was to indicate for how long the experiment in the closed PVC containers had to last to generate maximum differences between the treatments applied, with the air-stored control fruit representing the fastest ripening scenario. Based on the observations on the control fruit the experiment was finished after 32 days of storage. 
Fruit were stored for 32 days using a flowthrough system. A matrix of 32 different MA gas mixtures was generated by mixing flows of dry air, $\mathrm{O}_{2}$-free $\mathrm{N}_{2}$ and foodgrade $\mathrm{CO}_{2}$ (BOC, Palmerston North, NZ), to create combinations of eight different $\mathrm{O}_{2}$ levels $\left(0-21 \mathrm{kPa} \mathrm{O}_{2}\right)$ and four different $\mathrm{CO}_{2}$ levels $(0-15 \mathrm{kPa}$; Fig. 1). Before entering the $\mathrm{PVC}$ containers, the gas mixtures were humidified by bubbling through jars with water resulting in $\pm 98 \% \mathrm{RH}$. The flow rate was controlled at $0.151 \mathrm{~min}^{-1}$.

The MA conditions were held constant throughout the whole time span of the experiment (Fig. 1). The $\mathrm{CO}_{2}$ levels remained constant over time with an average S.E. of $\pm 0.50 \mathrm{kPa} \mathrm{CO}_{2}$, and the $\mathrm{O}_{2}$ levels stayed constant with an average S.E. of $\pm 0.32 \mathrm{kPa} \mathrm{O}_{2}$.

Gas conditions inside the containers were checked weekly by removing a sample using 100 $\mu l$ glass syringes and analysing them as described below. At the same time, respiration rates of the fruit were measured by temporarily closing the tubes to allow accumulation of $\mathrm{CO}_{2}$ and depletion of $\mathrm{O}_{2}$ by about $0.5 \mathrm{kPa}$. Depending on the MA conditions, this took between 1 and $3 \mathrm{~h}$.

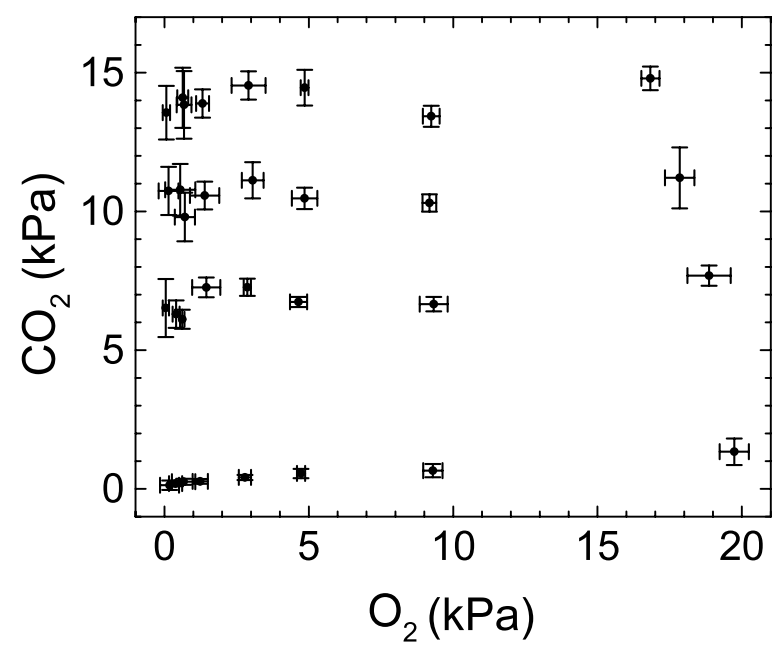

Fig. 1. Matrix of MA generated. The symbols indicate the average $\mathrm{O}_{2}$ and $\mathrm{CO}_{2}$ conditions as measured during the weekly routine checks, and the error bars indicate the S.D. of these measurements (eight in total) throughout the 32 days of the experiment.

\subsection{Low $\mathrm{CO}_{2}$ treatments}

Five containers were packed on the same day with 20 fruit each (average fruit weight of $240 \mathrm{~g}$ ) and stored at an air temperature of $7{ }^{\circ} \mathrm{C}$, applying $\mathrm{CO}_{2}$ levels ranging from 0 to $5 \mathrm{kPa}$. Fruit were stored for 52 days using a flow-through system. The gas mixtures were generated by mixing flows of dry air with foodgrade $\mathrm{CO}_{2}$ (BOC, Palmerston North, NZ). Before entering the containers, the gas mixtures were humidified by bubbling through jars with water resulting in $\pm 98 \% \mathrm{RH}$. The flow rate was controlled at $0.151 \mathrm{~min}^{-1}$. Gas conditions inside the containers were checked weekly by removing a sample using $100 \mu \mathrm{l}$ glass syringes and analysing them as described below.

\subsection{Gas analysis}

All gas samples were analysed using an $\mathrm{O}_{2}$ electrode (Citicell C/S type, City Technology Ltd., London, UK) in series with a miniature infrared $\mathrm{CO}_{2}$ transducer (Analytical Development Company, Hoddesdon, UK), with $\mathrm{O}_{2}-$ free $\mathrm{N}_{2}$ as carrier gas (flow rate $35 \mathrm{ml} \mathrm{min}^{-1}$ ). Output signals were linear over the range applied and analysed using HP integrators (Hewlett-Packard, model 3396A). Commercially prepared standards were used for calibrating the gas analysers. All samples were collected in duplicates through the two sampling ports of the containers. When duplicates differed by more than $0.1 \mathrm{kPa}$, new samples were taken and the system was checked for possible errors until consistent results could be obtained. Standard gases were routinely used to check for possible drift in the signal.

\subsection{Fruit measurements}

All fruit stored under MA conditions were measured at $20{ }^{\circ} \mathrm{C}$ for initial and final (after 32 days of storage) weight, firmness and colour. The separate batch of control fruit was monitored for firmness and colour on a weekly basis. Firmness and colour were measured at both base and stem end on pre-marked spots.

Firmness was measured non-destructively using a HandyHit (model 500-800, Fujihira Industry Co. 
Ltd., Japan), which has been proven useful for the assessment of avocado (Inoue and Tateishi, 2000) and kiwifruit firmness (Burdon et al., 1999). The Handyhit measures the elastic deformation of the tissue when compressed for $1 \mathrm{~mm}$ with a $6 \mathrm{~mm}$ diameter flat-ended plunger. The analogue gauge of the HandyHit device gives a reading between 0 (firm) and 100 (soft) corresponding with a compression force of, respectively, $800 \mathrm{~g}$ (or more) and $500 \mathrm{~g}$ (or less). The sensitivity of the device is such that it will only start to respond at the stage the fruit start to turn to black. Colour was measured as hue angle $(\mathrm{H})$ using a chromameter (model CR200, Minolta, Osaka, Japan) calibrated to a green plate.

$\mathrm{CO}_{2}$ injury was scored by estimating the percentage surface area affected and the depth of the injury of individual fruit. The injury consisted of round dark brown patches clearly distinctive against the green peel. At the late stages of ripening the patches became less obvious against the then purple-black colour of the peel. The flesh underneath these patches stayed firmer than the surrounding tissue. The percentage surface area affected was estimated using the following six classes: $0,0-10,10-25,25-50,50-75,75-$ 100 with increasing weights from 0 to 5 . The depth of the injury was scored by cutting the fruit and scoring the depth of the injury according to the following four classes: $0,0-5,5-10$ and 10-20 mm, assigning weights from 0 to 3 . The final injury index was calculated as the product of the weighted average for both indices.

\subsection{Data analysis}

All data collected were expressed according to the units proposed by Banks et al. (1995). Data were analysed statistically with the iterative nonlinear regression routine of STATISTICAL ANALYSIS SYSTEM (SAS software, version 6.11, SAS institute Inc., Cary, NC, USA). The non-linear equations were applied directly, without transformation to data or equations.

\section{Results and discussion}

\subsection{Gas exchange}

Under most of the MA conditions applied, gas exchange rates stayed constant throughout the experimental storage period. The fruit stored at 0 $\mathrm{kPa} \mathrm{CO}$ at 5,10 or $20 \mathrm{kPa} \mathrm{O}_{2}$ (Fig. 2), showed an increased rate of gas exchange, indicating a climacteric rise in the metabolic activity of these fruit between 7 and 14 days storage.

For the statistical analysis of the gas exchange data, the data averaged for the whole storage period were used to link the overall metabolic activity to the overall quality changes that occurred throughout the whole storage period. The averaged gas exchange data (plotted symbols from Figs. 3 and 4) showed typical Michaelis Menten type behaviour. The rate of $\mathrm{O}_{2}$ consumption $\left(r_{\mathrm{O}_{2}}\right)$ increased with increasing levels of $\mathrm{O}_{2}$ and decreased with increasing levels of $\mathrm{CO}_{2}$. The fact that the inhibiting effect of $\mathrm{CO}_{2}$ did not decrease with increasing $\mathrm{O}_{2}$ levels, indicated an uncompetitive type of $\mathrm{CO}_{2}$ inhibition (Hertog et al., 1998). The avocado fruit did not show a significant increase in their $\mathrm{CO}_{2}$ production $\left(r_{\mathrm{CO}_{2}}\right)$ as would be expected assuming alcoholic fermentation at low $\mathrm{O}_{2}$ levels (Fig. 4).

Yahia (1993) found that avocados showed an increased production of ethanol and acetaldehyde, and activity of anaerobic enzymes after 1 day exposure to $0.5 \% \mathrm{O}_{2}$, clearly indicating an in-

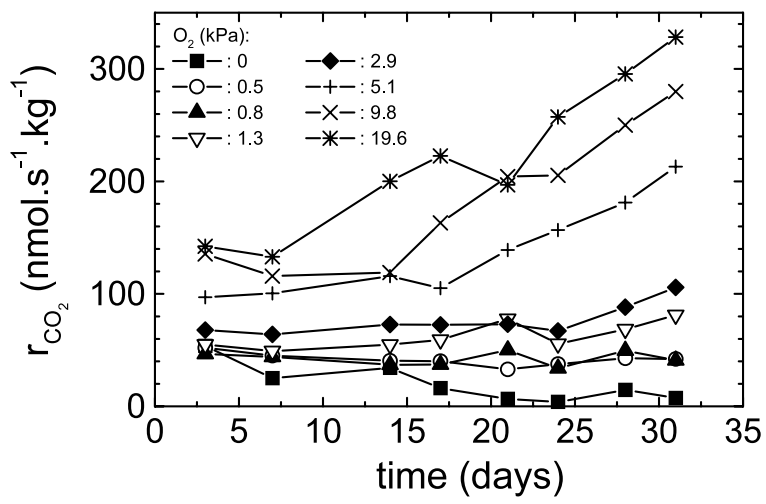

Fig. 2. $\mathrm{CO}_{2}$ production of 'Hass' avocado over time. The fruit were stored for 32 days at $7{ }^{\circ} \mathrm{C}, 0 \mathrm{kPa} \mathrm{CO}$, with a range of $\mathrm{O}_{2}$ levels $(0-20 \mathrm{kPa})$ as indicated in the legend. 


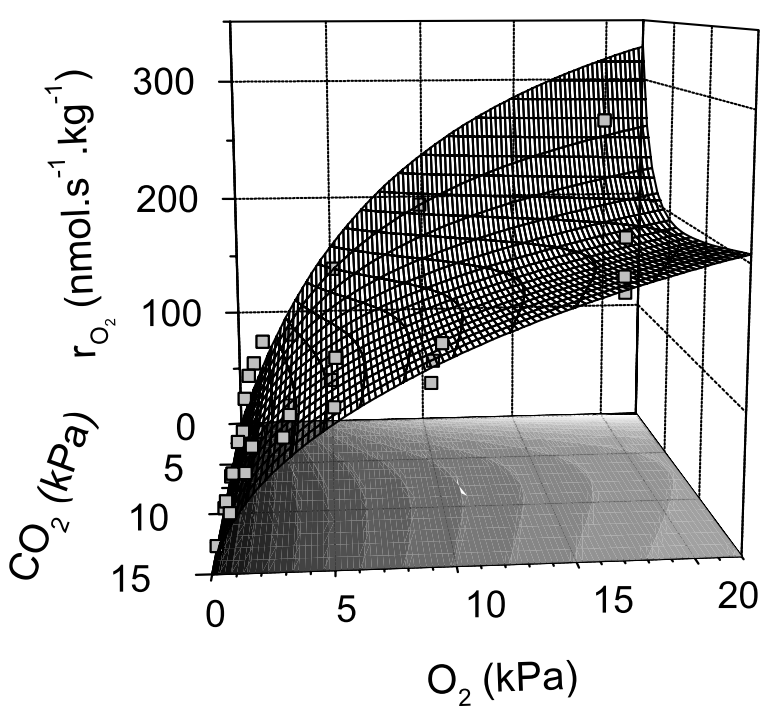

Fig. 3. $\mathrm{O}_{2}$ consumption of 'Hass' avocado fruit $\left(\mathrm{nmol} \mathrm{s} \mathrm{s}^{-1}\right.$ $\mathrm{kg}^{-1}$ ) stored at $7{ }^{\circ} \mathrm{C}$ as a function of $\mathrm{O}_{2}$ and $\mathrm{CO}_{2}$. Data points plotted represent the averaged measured data while the plane represents the model from Eq. (2) using the parameter estimates from Table 1. The contour lines emphasise the effect of $\mathrm{CO}_{2}$.

creased anaerobic activity. In spite of not showing an increased $r_{\mathrm{CO}_{2}}$, the fruit stored at $0 \mathrm{kPa} \mathrm{O}$ exhibited clear signs (off odours) of increased volatile production which were not identified. Given the rancid smell, one would expect these volatiles to originate from some part of fatty acid metabolism.

The $r_{\mathrm{CO}_{2}}$ at high $\mathrm{CO}_{2}$ levels in aerobic conditions was suppressed much more than the $r_{\mathrm{O}_{2}}$ (Fig. 4) resulting in a reduced respiratory quotient (RQ; Fig. 5). This change in RQ depending on $\mathrm{CO}_{2}$ (Fig. 5) might be explained by the fruit recycling its respiratory $\mathrm{CO}_{2}$ by phosphoenolpyruvate carboxylase fixing $\mathrm{CO}_{2}$ as malate (Blanke, 1991). In this case ATP production would be related to the total $r_{\mathrm{O}_{2}}$. Under the assumption that gas exchange rates can be linked to the rates of quality change processes, as the former is providing energy for the latter, the inhibiting effects of $\mathrm{MA}$ on $r_{\mathrm{O}_{2}}$ (Fig. 3) should be relative to the inhibiting effects of MA on colour change (Fig. 8B) and firmness loss (Fig. 9B). Prior analysis showed this was not the case. The rate of softening and colour change was much further suppressed than would be expected based on the suppression of the overall $r_{\mathrm{O}_{2}}$. One

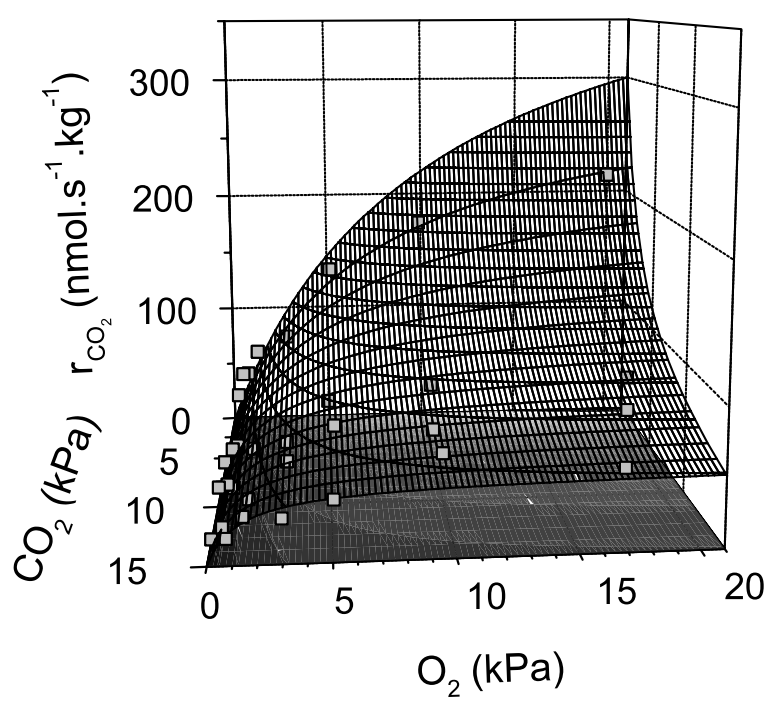

Fig. 4. $\mathrm{CO}_{2}$ production of 'Hass' avocado fruit (nmol s$\left.{ }^{-1} \mathrm{~kg}^{-1}\right)$ stored at $7{ }^{\circ} \mathrm{C}$ as a function of $\mathrm{O}_{2}$ and $\mathrm{CO}_{2}$. Data points plotted represent the averaged measured data while the plane represents the model from Eq. (2) using the parameter estimates from Table 1. The contour lines emphasise the effect of $\mathrm{CO}_{2}$.

could also argue whether the phosphoenolpyruvate carboxylase fixing capacity could be large enough to explain the observed drop in RQ as it will ultimately stop as a maximal amount of malate accumulates (Blanke, 1991).

Another explanation might be that because of the high $\mathrm{CO}_{2}$ levels, the mitochondrial respiration had shifted to the alternative respiratory pathway,

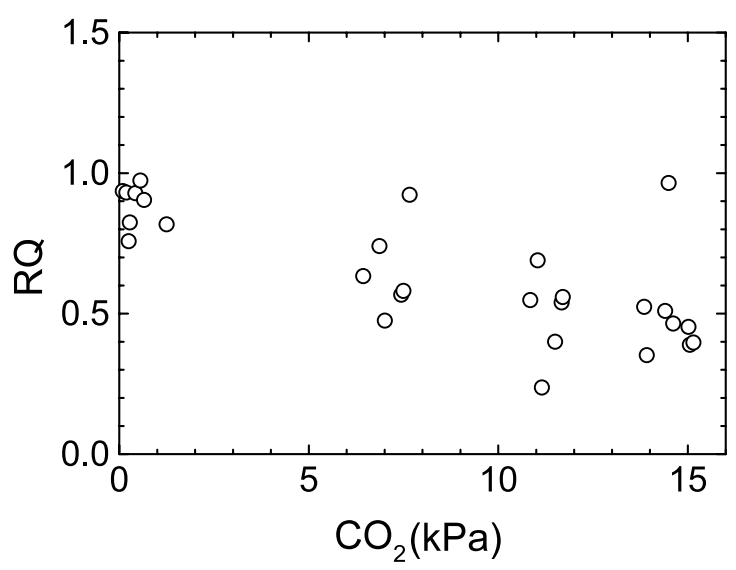

Fig. 5. RQ of 'Hass' avocado fruit stored for 32 days at $7{ }^{\circ} \mathrm{C}$ as a function of applied $\mathrm{CO}_{2}$ conditions. 
increasing the $\mathrm{O}_{2}$ consumption as a result of upregulation of alternative oxidase proteins. Lange and Kader (1997a,b,c) showed this effect for both isolated avocado mitochondria and whole fruit, and related this to the ripening stage of the fruit. This alternative non-phosphorylating respiratory pathway allows recycling of metabolic intermediates when the energy charge is high by bypassing oxidative phosphorylation (Lambers, 1982). According to Lange and Kader (1997a,a,b,c)), high $\mathrm{CO}_{2}$ in avocado could trigger both this alternative respiratory pathway and anaerobic pathways at the same time. Assuming the triggered anaerobic pathway is one that mainly results in volatile production without extra $\mathrm{CO}_{2}$ production (as observed at low $\mathrm{O}_{2}$ levels), the increased $\mathrm{O}_{2}$ consumption due to up-regulation of the alternative oxidase could explain the observed reduction in RQ. ATP production would be related to just that part of $r_{\mathrm{O}_{2}}$ used in the oxidative phosphorylation which is relative to the observed $r_{\mathrm{CO}_{2}}$.

The data were analysed using Michaelis Menten type gas exchange models using the uncompetitive type of $\mathrm{CO}_{2}$ inhibition (Hertog et al., 1998). Assuming the change in RQ was due to activation of the alternative respiratory pathway, the gas exchange model was extended to include this phenomenon. A simplified pathway was assumed, describing how an alternative oxidase (AOX) is regulated by the presence of $\mathrm{CO}_{2}$ to oxidise the large flow of electrons $\left(\mathrm{e}^{-}\right)$through an intermediate enzyme substrate complex (AC).

$$
\begin{aligned}
\mathrm{e}^{-}+ & \mathrm{O}_{2}+\mathrm{CO}_{2}+\mathrm{AOX} \underset{k_{-1}}{\stackrel{k_{1}}{\rightleftarrows}} \mathrm{AC} \stackrel{k_{\mathrm{p}}}{\rightarrow} \mathrm{CO}_{2}+\mathrm{H}_{2} \mathrm{O} \\
& +\mathrm{AOX}
\end{aligned}
$$

The large flow of $\mathrm{e}^{-}$is believed to be generated by fermentative pathways induced by the high $\mathrm{CO}_{2}$ levels and is assumed not to be rate limiting. The active complex AC is assumed to be in steady state with its constituents. The steady state reaction is characterised by its forward and backward reaction rates $k_{1}$ and $k_{-1}$. The reaction rate for the final reaction step is given by $k_{\mathrm{p}}$. For this case, $\mathrm{O}_{2}$ consumption by $\mathrm{AOX}\left(r_{\mathrm{O}_{2}}{ }^{\mathrm{AOX}}\right)$ can be described according to:
$r_{\mathrm{O}_{2}}^{\mathrm{AOX}}=\frac{r_{\mathrm{O}_{2}}^{\mathrm{AOX}, \text { max }} p_{\mathrm{O}_{2}} p_{\mathrm{CO}_{2}}}{K m_{\mathrm{O}_{2}}^{\mathrm{AOX}, \text { max }}+p_{\mathrm{O}_{2}} p_{\mathrm{CO}_{2}}},\left\{\begin{array}{l}r_{\mathrm{O}_{2}}^{\mathrm{AOX}, \text { max }}=k_{\mathrm{p}} \mathrm{AOX} \\ K m_{\mathrm{O}_{2}}^{\mathrm{AOX}, \text { max }}=\frac{k_{-1}+k_{\mathrm{p}}}{k_{1}}\end{array}\right.$

where $p_{\mathrm{O} 2}$ and $p_{\mathrm{CO} 2}$ are the partial pressures for $\mathrm{O}_{2}$ and $\mathrm{CO}_{2}$ (both in $\mathrm{kPa}$ ); $r_{\mathrm{O}_{2}}{ }^{\text {AOX, max }}$ is the maximum oxidative $\mathrm{O}_{2}$ consumption rate by $\mathrm{AOX}\left(\mathrm{mol} \mathrm{kg}^{-1}\right.$ $\mathrm{s}^{-1}$ ) unconstrained by $\mathrm{O}_{2}$ or $\mathrm{CO}_{2} ; \mathrm{Km}_{\mathrm{O}_{2}}{ }^{\mathrm{AOX}}$ (in $\mathrm{kPa}^{2}$ ) is the Michaelis constant for the $\mathrm{O}_{2}$ consumption by AOX. This alternative oxidase is regulated by the presence of $\mathrm{CO}_{2}$ but does not produce $\mathrm{CO}_{2}$.

Total $\mathrm{O}_{2}$ consumption $r_{\mathrm{O}}$ was assumed to be the combined result of $r_{\mathrm{O}_{2}}{ }^{\mathrm{AOX}}$ and $\mathrm{O}_{2}$ consumption by the normal oxidative phosphorylation $\left(r_{\mathrm{O}_{2}}{ }^{\mathrm{OX}}\right)$ as described by the standard Michaelis Menten type gas exchange model using the uncompetitive type of $\mathrm{CO}_{2}$ inhibition (Hertog et al., 1998). $\mathrm{CO}_{2}$ production was linked to the oxidative phosphorylation only. This resulted in:

$r_{\mathrm{O}_{2}}^{\mathrm{OX}}=\frac{r_{\mathrm{O}_{2}}^{\mathrm{OX}, \max } p_{\mathrm{O}_{2}}}{K m_{\mathrm{O}_{2}}^{\mathrm{OX}}+p_{\mathrm{O}_{2}}\left[1+p_{\mathrm{CO}_{2}} / K m u_{\mathrm{CO}_{2}}^{\mathrm{OX}}\right]}$

$r_{\mathrm{O}_{2}}=r_{\mathrm{O}_{2}}^{\mathrm{OX}}+r_{\mathrm{O}_{2}}^{\mathrm{AOX}}$

$r_{\mathrm{CO}_{2}}=R Q \cdot r_{\mathrm{O}_{2}}^{\mathrm{OX}}$

where $r_{\mathrm{O}_{2}}{ }^{\mathrm{OX}, \max }$ is the maximum $\mathrm{O}_{2}$ consumption rate $\left(\mathrm{mol} \mathrm{kg}^{-1} \mathrm{~s}^{-1}\right)$ by oxidative phosphorylation unconstrained by $\mathrm{O}_{2} ; \mathrm{Km}_{\mathrm{O}_{2}}$ Ox and $\mathrm{Kmu}_{\mathrm{CO}_{2}}$ OX (both in $\mathrm{kPa}$ ) are the Michaelis constants for respiration and the uncompetitive inhibition of respiration by $\mathrm{CO}_{2}$, respectively. The parameter estimates are given in Table 1. The simulated model values using these parameter estimates are represented by the planes in Figs. 3 and 4 .

There is only a limited amount of literature on the gas exchange rates to which we can compare our results. Most work on gas exchange rates of avocado was done by Eaks (1976, 1978, 1980, 1983 ) but covered mainly rates at $20{ }^{\circ} \mathrm{C}$ after exposure to different chilling temperatures. However, our results seem to fit within the common knowledge on avocado, confirming its relatively high metabolic activity as compared with, for instance, apple or tomato, which have gas ex- 
Table 1

Parameter estimates and their S.E. resulting from the non-linear regression analysis of gas exchange and colour change rates of 'Hass' avocado fruit as a function of $\mathrm{O}_{2}$ and $\mathrm{CO}_{2}$

\begin{tabular}{|c|c|c|c|}
\hline \multicolumn{2}{|c|}{ Gas exchange data } & \multicolumn{2}{|c|}{ Colour change data } \\
\hline Parameter $^{\mathrm{a}}$ & Estimate (S.E.) ${ }^{\mathrm{c}}$ & Parameter $^{\mathrm{b}}$ & Estimate (S.E.) ${ }^{c}$ \\
\hline$r_{\mathrm{O}}$ OX,max & $484(15)$ & $K_{\mathrm{H}}^{\mathrm{f}}$ & $0.19(8)$ \\
\hline$K m_{\mathrm{O}_{2}}$ ox & $10.5(23)$ & $K m_{\mathrm{f}}$ & $0.91(36)$ \\
\hline $\mathrm{Km}_{\mathrm{CO}_{2}} \mathrm{OX}$ & $1.96(25)$ & & \\
\hline$r_{\mathrm{O}}{ }^{\mathrm{AOX}, \text { max }}$ & $334(51)$ & & \\
\hline$K^{2} \mathrm{~m}_{\mathrm{O}_{2}}^{\mathrm{AOX}}$ & $389(76)$ & & \\
\hline$R Q^{2}$ & $0.93(7)$ & & \\
\hline$R^{2}(\%)^{\mathrm{d}}$ & 97 & & 98 \\
\hline$n$ & 64 & & 32 \\
\hline
\end{tabular}

${ }^{\text {a }} r_{\mathrm{O}}{ }^{\max }$ is the maximum oxidative $\mathrm{O}_{2}$ consumption rate (nmol kg ${ }^{-1} \mathrm{~s}^{-1}$ ) unconstrained by $\mathrm{O}_{2} ; \mathrm{Km}_{\mathrm{O}_{2}}$ and $\mathrm{Kmu}_{\mathrm{CO}_{2}}$ (both in $\mathrm{kPa}$ ) are the Michaelis constants for, respectively, respiration and uncompetitive inhibition of respiration by $\mathrm{CO}_{2} ; R Q_{\mathrm{OX}}$ is the respiration quotient for oxidative respiration

${ }^{\mathrm{b}} k_{\mathrm{H}}^{\mathrm{f}}$ is the maximum rate of colour change under anaerobic conditions; $K m_{\mathrm{f}}$ is the Michaelis constant for the inhibition of this anaerobic process by $\mathrm{O}_{2}$.

${ }^{c}$ S.E. are expressed as a percentage of the parameter value.

d $R^{2}$, percentage variance accounted for; $n$, number of observations.

change rates five times lower at $7{ }^{\circ} \mathrm{C}$ (Hertog et al., 1998). The postulated mechanism from Eq. (2) was able to explain $97 \%$ of the observed variation in gas exchange rates and is consistent with literature data on the effects of elevated $\mathrm{CO}_{2}$ on alternative oxidase activity.

\subsection{Weight loss}

During the 32 days of the experiment, fruit lost about $0.4-1.8 \%$ of their initial weight, depending on the MA conditions applied (Fig. 6). Weight loss mainly consists of water loss through transpiration and carbon loss through gas exchange (Maguire et al., 2001).

The metabolic change observed in the gas exchange data resulting in an RQ of 0.5 (for each mole of $\mathrm{O}_{2}$ consumed, only half a mole of $\mathrm{CO}_{2}$ is being released) implied fruit would have gained net weight at high $\mathrm{CO}_{2}$ treatments. As this was not observed the fruit must have lost weight through other means.
Based on the modelled gas exchange and estimates of transpiration assuming an average water vapour permeance of avocado fruit of 60 nmol s${ }^{-1} \mathrm{~m}^{-2} \mathrm{~Pa}^{-1}$ (Johnston and Banks, 1998) and an average relative humidity of $98 \%$, the expected weight losses at $0 \mathrm{kPa} \mathrm{CO}_{2}$ could be largely explained (Fig. 6). However, avocado fruit developed larger weight losses at low $\mathrm{O}_{2}$ levels and at increased $\mathrm{CO}_{2}$ levels than was expected based on transpiration and gas exchange rates. The only possible way to explain this gap in the mass balance is by assuming a certain volatile production at both low $\mathrm{O}_{2}$ levels (induced by anaerobic conditions) and increased $\mathrm{CO}_{2}$ levels (in aerobic conditions). The volatiles generated under both conditions do not necessarily have to be the same.

Ethylene could be a possible candidate for the volatile produced at increased $\mathrm{CO}_{2}$ levels at aerobic conditions. However, there is no reason why ethylene would only be produced at increased $\mathrm{CO}_{2}$ levels and not at $0 \mathrm{kPa} \mathrm{CO}$ especially as high $\mathrm{CO}_{2}$ is known to completely inhibit ethylene production of preclimacteric fruit (Lange and Kader, 1997a). Also, if the weight loss unaccounted for was to be completely attributed to

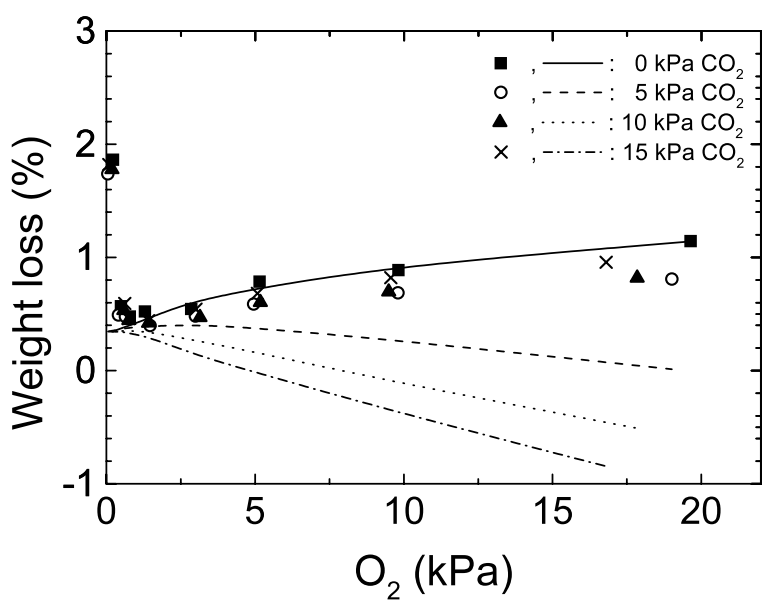

Fig. 6. Weight loss of 'Hass' avocado fruit stored for 32 days at $7{ }^{\circ} \mathrm{C}$ as a function of the MA conditions applied. Weight loss is expressed as a percentage of the initial weight. Plotted symbols represent the measured data while the lines represent the weight loss expected based on modelled gas exchange and transpiration rates. A negative value indicates weight gain. The difference between modelled and measured resembles the unaccounted carbon loss due to volatile production. 
ethylene production, this would imply an average ethylene production during the 32 days of storage at $15 \mathrm{kPaCO}$ of about $250 \mathrm{nmol} \mathrm{s}^{-1} \mathrm{~kg}^{-1}$ which is about 100 times the literature values generally found for avocado fruit in their climacteric phase (Eaks, 1978, 1980, 1983). In other words, assuming average values, ethylene production could only explain $1 \%$ of the observed gap in the mass balance and some other volatile must have been responsible for the observed gap in the mass balance.

\subsection{Colour}

Avocado fruit ripened to different degrees, as measured by change of colour, with differing MA conditions (Fig. 7). Generally the stem end coloured faster than the base of the fruit (results not shown), but the responses to the applied MA conditions were similar. The results will be discussed using the data coming from the stem end of the fruit. The largest change in hue was observed at high $\mathrm{O}_{2}$ and low $\mathrm{CO}_{2}$ levels (Fig. 7). The minimum change in hue was observed around 1$2 \mathrm{kPa} \mathrm{O}_{2}$, corresponding to where the minimum weight loss was observed (Fig. 6). Colour change at low $\mathrm{O}_{2}$ levels is apparently also driven by anaerobic processes not visible from the normal gas exchange (Figs. 3 and 4). The observed response of colour change to MA conditions was

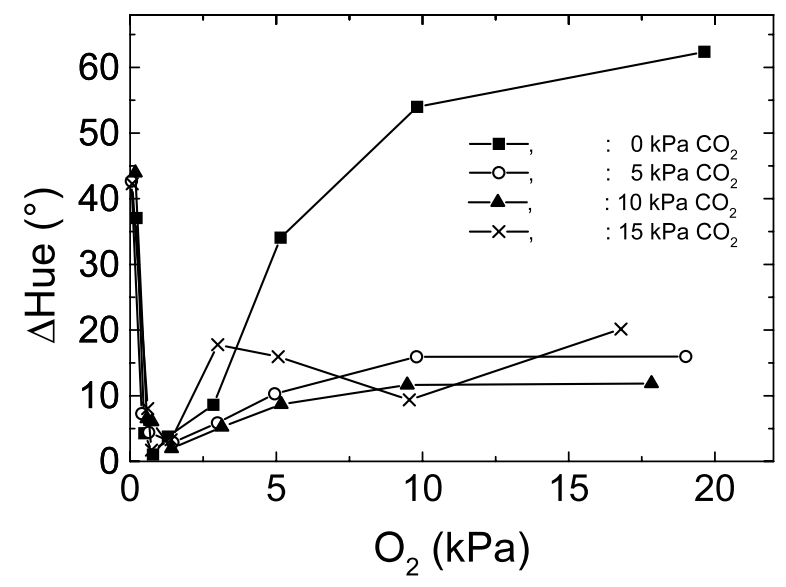

Fig. 7. Change in hue $\left({ }^{\circ}\right)$ of 'Hass' avocado fruit stored for 32 days at $7{ }^{\circ} \mathrm{C}$ as a function of the MA conditions applied. The colour was measured at the stem end of the fruit. comparable to that observed by Meir et al. (1995), although they did not report an increased colour change under anaerobic conditions as they did not measure below $3 \mathrm{kPa} \mathrm{O}$.

Just as the rate of softening of apple depended on the MA conditions via the energy provided by the gas exchange (Hertog et al., 2001), we would expect the rate of colour change to depend on the MA conditions. With apple softening, Hertog et al. (2001) assumed that softening was linear over the short time interval the fruit were monitored. For the current work on avocado this assumption is not valid, and the complete non-linear behaviour of colour change with time needs to be taken into account (Fig. 8A).

Hertog (2002) applied the following model to colour change of avocado describing hue $\left(H\right.$ in $\left.{ }^{\circ}\right)$ during time ( $t$ in days):

$$
\begin{aligned}
& H_{t}=H_{+\infty}+\frac{H_{-\infty}-H_{+\infty}}{1+e^{k_{H} t} \cdot\left(H_{-\infty}-H_{0}\right) /\left(H_{0}-H_{+\infty}\right)}, \\
& H_{-\infty}=(1+C) \cdot H_{0}
\end{aligned}
$$

with the two asymptotic hue values $\left(H_{+\infty}\right.$ and $H_{-\infty}$ both in ${ }^{\circ}$ ) at plus and minus infinite time, the rate constant $K_{H}\left(\right.$ day $\left.^{-1}\right)$ and the initial hue value $H_{0}\left({ }^{\circ}\right) . H_{-\infty}$, was defined relative to $H_{0}$ through the batch specific parameter $C$. The rate constant for storage in air at $7{ }^{\circ} \mathrm{C}$ was $k_{H}^{\mathrm{RA}}=0.213$ per day, while $H_{+\infty}$ was set at $35^{\circ}$ (Hertog, 2002). For the control fruit from Fig. 8A, $C$ was estimated to be 0.00194 , with $H_{0}$ set to the initial measured hue value of $122.2^{\circ}$.

Depending on the MA conditions under which the fruit were stored, we would expect the rate constant $k_{H}$ to vary depending on the gas exchange rates. However, comparing Fig. 7 with Fig. 4 showed that the increased colour change at low $\mathrm{O}_{2}$ levels cannot be explained by increased anaerobic activity in terms of $r_{\mathrm{CO}_{2}}$. There was also a clear difference between the normal colour change under aerobic and the defective colour change under anaerobic conditions; while the fruit turned purple black under aerobic conditions due to normal anthocyanin formation, they turned greyish green under anaerobic conditions. This indicated that a different process governed the colour change under anaerobic conditions. To describe 

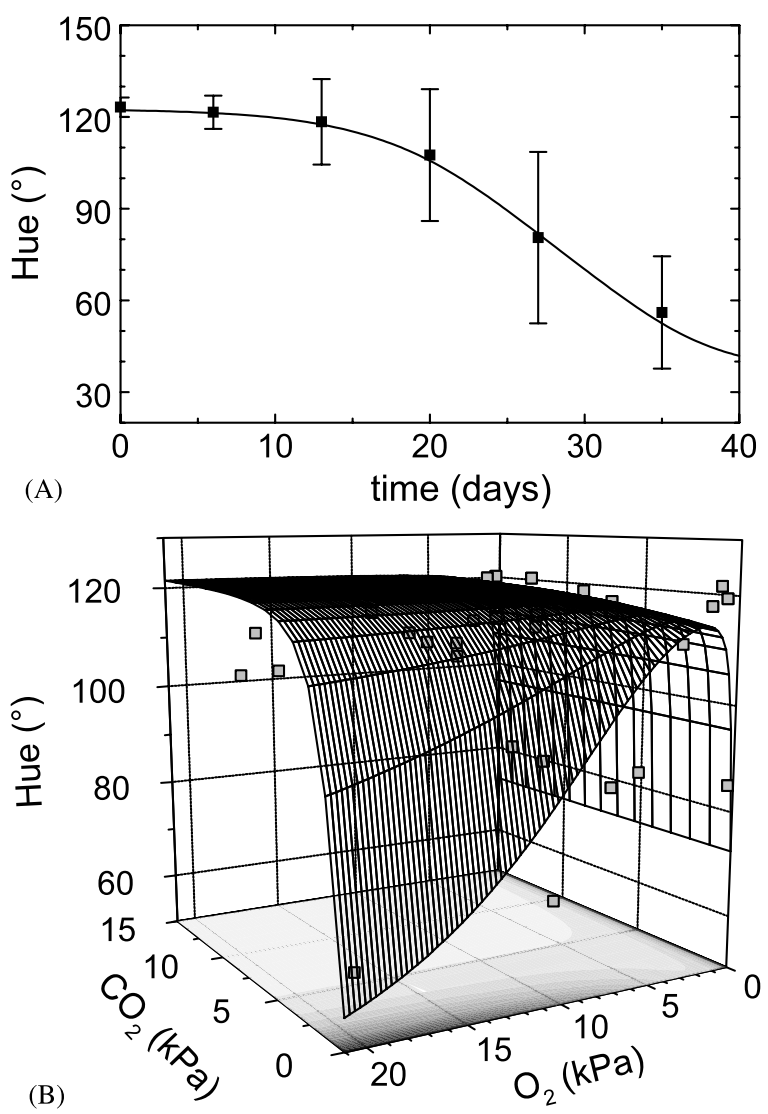

Fig. 8. Hue colour $\left({ }^{\circ}\right)$ of the stem end of 'Hass' avocado fruit stored at $7{ }^{\circ} \mathrm{C}$ with (A) representing the observed time course for the control fruit and (B) the final hue of the MA stored fruit as a function of the MA conditions applied. The plotted symbols represent the average of the measured data with the error bars representing the S.D. due to fruit-to-fruit variation. The line from (A) is fitted using the model from Eq. (3) while the plane $(\mathrm{B})$ represent the final colour prediction based on the modelled gas exchange rates (Eqs. (2)-(4)).

colour change of avocado fruit, the rate constant $k_{H}$ was therefore linked to the relative metabolic rate (Tijskens, 1996; Hertog et al., 1999) describing the aerobic colour change process. As the $r_{\mathrm{O}_{2}}{ }^{\text {AOX }}$ was assumed not to result in any ATP production, the aerobic colour change process was linked to $r_{\mathrm{O}_{2}}{ }^{\text {OX }}$ only. The colour change model was further extended with an anaerobic term analogous to the term generally applied to describe fermentative $\mathrm{CO}_{2}$ production (Peppelenbos et al., 1996). This resulted in the following equation for the rate of colour change as a function of the MA conditions:
$k_{\mathrm{H}}=k_{\mathrm{H}}^{\mathrm{RA}} \frac{r_{\mathrm{O}_{2}}^{\mathrm{OX}, \mathrm{MA}}}{r_{\mathrm{O}_{2}}^{\mathrm{OX}, \mathrm{RA}}}+\frac{k_{\mathrm{H}}^{\mathrm{f}}}{1+\mathrm{O}_{2} / K m_{\mathrm{f}}}$

with $r_{\mathrm{O}_{2}}$ OX,MA the $\mathrm{O}_{2}$ consumption rate by oxidative phosphorylation at certain MA conditions; $r_{\mathrm{O}_{2}}$ OX,RA the $\mathrm{O}_{2}$ consumption rate by oxidative phosphorylation in regular air; $k_{\mathrm{H}}^{\mathrm{f}}$ the maximum rate of colour change under anaerobic conditions and $K m_{\mathrm{f}}$ the Michaelis constant for the inhibition of this anaerobic process by $\mathrm{O}_{2}$.

The colour data were analysed by applying this integrated approach combining Eqs. (2)-(4) using the parameter values already established, and estimating the two additional parameters $k_{\mathrm{H}}^{\mathrm{f}}$ and $K m_{\mathrm{f}}$. Over $98 \%$ of the variation in the final colour of the MA stored avocado fruit was explained by the model (Fig. 8B; Table 1).

\subsection{Firmness}

On average, the control fruit stored in air (Fig. 9A) did not soften sufficiently to reach a firmness of 100. Generally, the stem end softened faster than the base of the fruit (results not shown), but the responses to the applied MA conditions were similar. The results will be discussed using the data coming from the stem end of the fruit.

In analogy to the colour data, a simple logistic model was used to describe the firmness data in function of time:

$F(t)=\frac{F_{+\infty}}{1+e^{-k_{F} \cdot t} \cdot\left(F_{+\infty}-F_{0}\right) / F_{0}}$

with the asymptotic firmness values $\left(F_{+\infty}=100\right)$ at plus infinite time, the rate constant $k_{\mathrm{F}}$ (per day) and the initial firmness value $F_{0}$ (in HandyHit units). Analysing the control data with this model (Fig. 9A) resulted in values for the rate constant $k_{\mathrm{F}}$ valid for air conditions at $7{ }^{\circ} \mathrm{C}$ of $k_{\mathrm{F}}^{\mathrm{RA}}=0.1633$ per day and a value for $F_{0}$ of 0.36 .

The same approach applied to the colour data was followed to predict the firmness data after storage at the different MA conditions by making the rate of softening $k_{\mathrm{F}}$ dependent on the relative metabolic rate according to: 


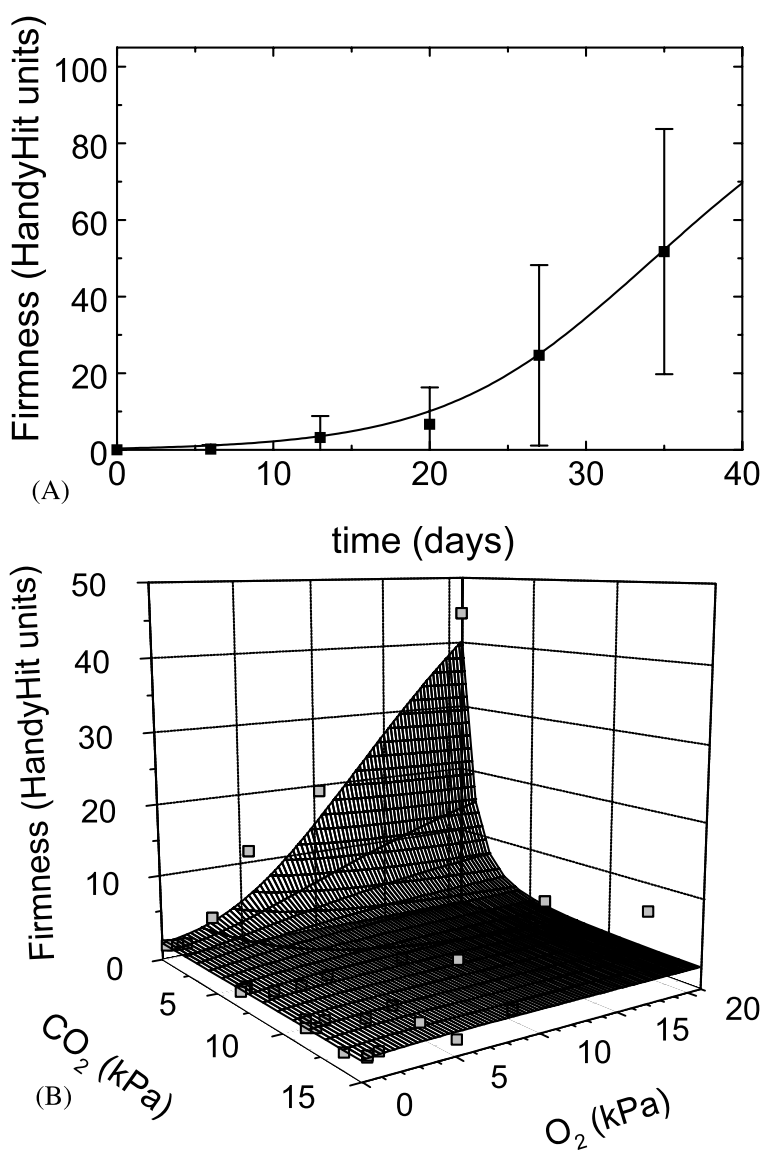

Fig. 9. Firmness (HandyHit units) of the stem end of 'Hass' avocado fruit stored at $7{ }^{\circ} \mathrm{C}$ with (A) representing the observed time course for the control fruit and (B) the final firmness of the MA stored fruit as a function of the MA conditions applied. The plotted symbols represent the average of the measured data with the error bars representing the S.D. due to fruit-to-fruit variation. The line from (A) is fitted using the model from Eq. (5) while the plane (B) represent the final firmness prediction based on the modelled gas exchange rates (Eqs. (2), (5) and (6)).

$k_{\mathrm{F}}=k_{\mathrm{F}}^{\mathrm{RA}} \frac{r_{\mathrm{O}_{2}}^{\mathrm{OX}, \mathrm{MA}}}{r_{\mathrm{O}_{2}}^{\mathrm{OX}, \mathrm{RA}}}$

This time no additional anaerobic term was added, as fruit did not show increased softening under anaerobic conditions (Fig. 9B). It needs to be emphasised that in this approach to describe softening at MA conditions, the model was not fitted to the data but the model was applied using the estimated parameter values on the gas exchange data in combination with the estimated parameter values on the softening of the air stored control fruit, assuming the rate of softening of the MA stored fruit depended on the relative metabolic rate according Eq. (6).

We realise that the model used to describe softening is a crude simplification of the whole softening process ignoring all details on the involvement of ethylene and a whole range of enzymes. However, the message that can be learned from this simplified approach is that MA was inhibiting the rate of softening to the same extend as it was inhibiting the metabolic rate as expressed by $r_{\mathrm{O}_{2}}$ OX.

The results (Fig. 9B) showed a good agreement between measured and predicted values with the model explaining about $91 \%$ of the observed variation. The observed response of softening under MA conditions was comparable with the observations of Meir et al. (1995) of increasing inhibition of fruit softening with decreasing levels of $\mathrm{O}_{2}$ and increasing levels of $\mathrm{CO}_{2}$.

\section{5. $\mathrm{CO}_{2}$ injury}

Depending on the MA conditions applied, the fruit coming out of storage showed varying levels of what we believe was $\mathrm{CO}_{2}$ injury (Fig. 10).

The injury was similar to that reported by Meir et al. (1995), however, our fruit showed some different responses to the applied MA conditions. Meir et al. related the injury to either high $\mathrm{CO}_{2}(8$ $\mathrm{kPa})$ or low $\mathrm{O}_{2}(3 \mathrm{kPa})$ levels, but injury did not occur at high $\mathrm{CO}_{2}$ in combination with high $\mathrm{O}_{2}(21$ $\mathrm{kPa}$ ) levels. In the current experiment, fruit indeed showed increasing injury with increasing $\mathrm{CO}_{2}$ levels, but no reduction at $21 \mathrm{kPa} \mathrm{O}_{2}$ (Fig. 10). In contrast, the injury level was reduced with lowering levels of $\mathrm{O}_{2}$. The fruit stored at $0 \mathrm{kPa}$ $\mathrm{CO}_{2}$ also showed increased injury levels at $\mathrm{O}_{2}$ levels below $2 \mathrm{kPa}$. At $0 \mathrm{kPaO} \mathrm{O}_{2}$ this injury never occurred, but fruit were unacceptable because of their general anaerobic state.

The results contrast with earlier work on 'Fuerto' avocado stored for up to 60 days under $2 \mathrm{kPa} \mathrm{O}_{2}$ and $10 \mathrm{kPa} \mathrm{CO}$ that incurred less injury than control fruit (Allwood and Cutting, 1994). 'Hass' avocado stored at $5{ }^{\circ} \mathrm{C}$ and $2 \mathrm{kPa} \mathrm{O}_{2}$ benefited from increased levels of $\mathrm{CO}_{2}(2.5 \mathrm{kPa})$ to 


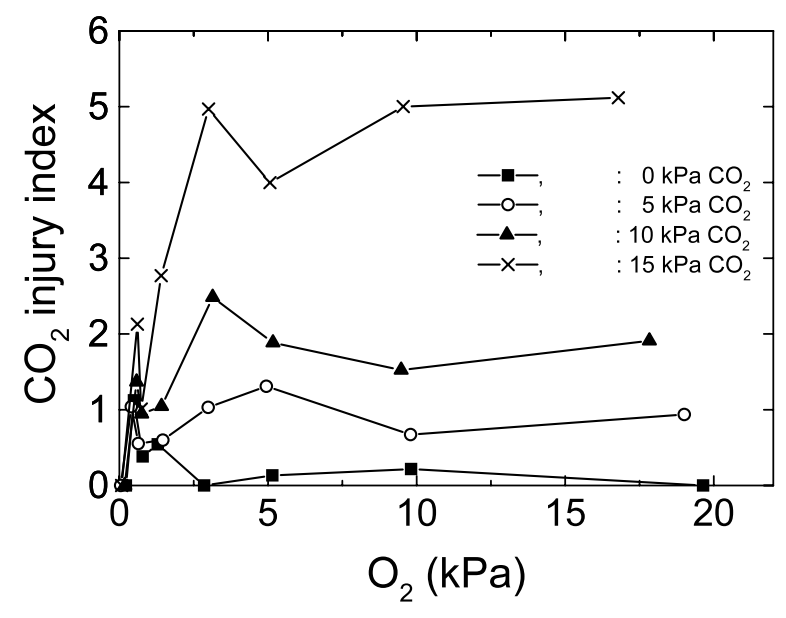

Fig. 10. $\mathrm{CO}_{2}$ injury of 'Hass' avocado fruit after 32 days storage at $7{ }^{\circ} \mathrm{C}$ as a function of the MA conditions applied. The index was based on the surface area and the depth of underlying pulp affected.

suppress flesh discoloration (Faubian et al., 1992) although increasing $\mathrm{CO}_{2}$ to $10 \mathrm{kPa}$ resulted in increased discoloration again.

Based on our results we can not conclude whether the $\mathrm{CO}_{2}$ injury was the direct result of the high $\mathrm{CO}_{2}$ levels or an indirect effect because of injury due to the volatiles induced by the high $\mathrm{CO}_{2}$ levels. A conservative recommendation to prevent quality losses due to high $\mathrm{CO}_{2}$, would be to keep the $\mathrm{CO}_{2}$ level during storage of 'Hass' avocado below $5 \mathrm{kPa}$.

\subsection{Low $\mathrm{CO}_{2}$ treatment}

To examine the effect of low levels of $\mathrm{CO}_{2}$ a second experiment was completed, measuring firmness and hue over time during storage at $7{ }^{\circ} \mathrm{C}$ and applying $\mathrm{CO}_{2}$ levels ranging from 0 to $5 \mathrm{kPa}$ (Fig. 11). The data clearly showed how an increasing level of $\mathrm{CO}_{2}$ increasingly inhibited both the rate of softening and the rate of colour change.

The results were compared with the models established above. Given the large time difference between the two experiments (February vs. November of the same year) and the potential difference in harvest maturity, the batch-dependent parameters were estimated again, while all other parameters were kept at their previously estimated values. In spite of this potential maturity difference we assumed that the underlying principles did not change.

For colour, $H_{0}$ was set to the measured initial hue of $127.4^{\circ}$, while $C$ was estimated to be 0.00254 explaining $99 \%$ of the observed variation. For firmness, $F_{0}$ was estimated to be 0.0892 explaining $83 \%$ of the observed variation.

The results clearly show that the same principles applied; the relationship established for the high $\mathrm{CO}_{2}$ levels was also able to explain the observed responses to the range of low $\mathrm{CO}_{2}$ levels applied. It also confirmed that the rates of colour change and softening were related to the $r_{\mathrm{O}_{2}}{ }^{\mathrm{OX}}$ only and not the overall $r_{\mathrm{O}_{2}}$.

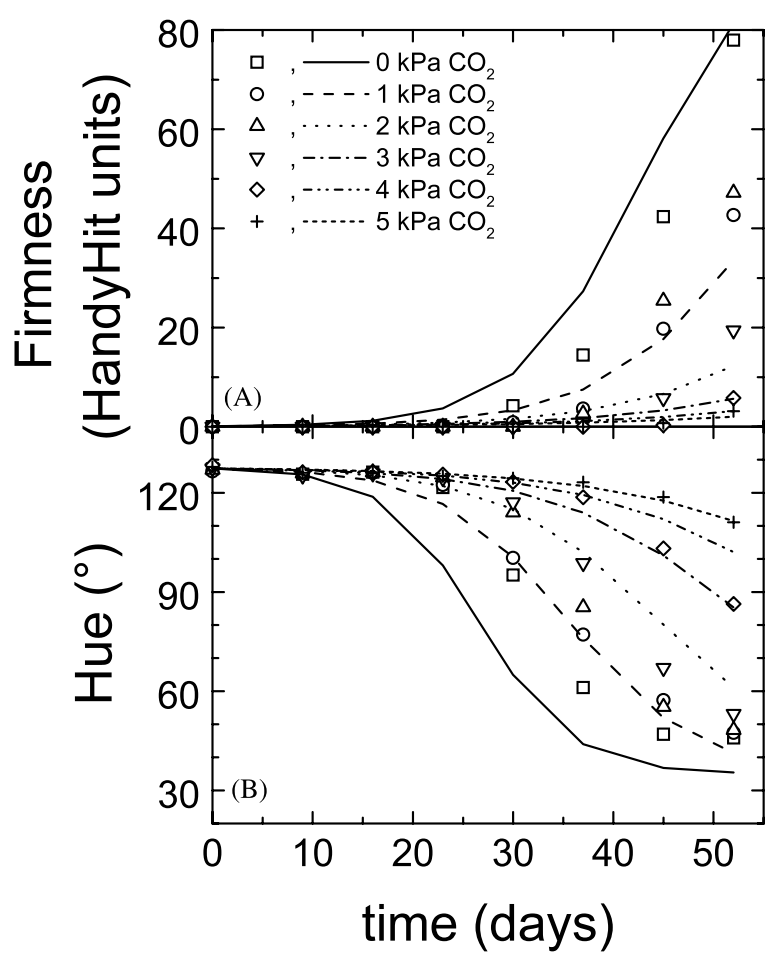

Fig. 11. Firmness (A) and hue (B) of 'Hass' avocado fruit stored for 52 days at $7{ }^{\circ} \mathrm{C}$ at $\mathrm{CO}_{2}$ levels ranging from 0 to 5 $\mathrm{kPa}$. Firmness and hue were measured at the stem end of the fruit. Plotted symbols represent the measured data while the lines represent the predictions based on the modelled gas exchange rates. 


\section{Optimal MA conditions}

Control fruit stored in air and the $0 \mathrm{kPa} \mathrm{CO}_{2}$ stored fruit at the higher $\mathrm{O}_{2}$ levels reached eating quality at the end of the 32 days of storage, exhibiting normal ripening characteristics. Fruit stored at $0 \mathrm{kPa} \mathrm{O} \mathrm{O}_{2}$ were unacceptable because of their general anaerobic state. The fruit stored at $10-15 \mathrm{kPa} \mathrm{CO}_{2}$ were mostly unacceptable because of the incurred $\mathrm{CO}_{2}$ injury and their firm state. The remaining fruit would need an additional shelf life to reach eating quality.

Taking all the different aspects together, the optimum MA conditions for the studied batch of avocado fruit stored for 32 days at $7{ }^{\circ} \mathrm{C}$ was around $2 \mathrm{kPa} \mathrm{O}_{2}$ and $0 \mathrm{kPa} \mathrm{CO}_{2}$. Under these conditions no $\mathrm{CO}_{2}$ injury occurred (Fig. 10), the change in hue was minimal (Fig. 7), weight loss was minimised (Fig. 6), and softening was almost completely inhibited (Fig. 9B). At such low $\mathrm{O}_{2}$ levels, no additional benefit was found from raising the levels of $\mathrm{CO}_{2}$.

However, it would go too far to recommend these conditions as the optimal storage conditions for avocado fruit as too many variables were not covered. This work was done for only one temperature, so the temperature dependencies of all the involved processes have not been characterised, and results can not be easily extrapolated to other temperatures. Even though one would assume that the underlying principles are the same for different avocado cultivars, one should also realise that different cultivars can respond in different extends to the same variables as is illustrated by the positive effect of $10 \mathrm{kPa} \mathrm{CO}_{2}$ on 'Fuerto' avocado (Allwood and Cutting, 1994).

Due to the relative high storage temperature of $7{ }^{\circ} \mathrm{C}$, chilling injury did not occur in the current experimental setup. As MA is known to interact with chilling injury (Pesis et al., 1994) certain combinations of low temperature storage might be feasible as long as the proper MA conditions are applied to prevent chilling injury.

As if this is not enough, considerable variation can be expected between batches due to maturity differences at harvest. As long as the maturity dependent batch specific parameters can be identified and quantified at harvest, the developed models can be used to predict quality aspects of particular batches instead of only giving a general indication for the average 'Hass' avocado fruit.

Assuming the above mentioned issues have been addressed, well founded recommendations can be made for the storage of a particular batch of avocado fruit taking into account characteristics of both the product and the intended postharvest chain.

\section{Acknowledgements}

This work was funded by the New Zealand Foundation for Research, Science and Technology (MAUAX008). Our thanks goes to our colleagues Bruce Mackay, John Mawson and Ximenita Trejo Araya for reviewing the original manuscript and the referees for their critical but valuable feedback.

\section{References}

Allwood, M.E., Cutting, J.G.M., 1994. Progress report: gas treatment of 'Fuerto' avocados to reduce cold damage and increase storage life. Suid-Afrikaans Avokadokwekersvereniging Jaarboek 17, 22-26.

Banks, N.H., Cleland, D.J., Cameron, A.C., Beaudry, R.M., Kader, A.A., 1995. Proposal for a rationalized system of units for postharvest research in gas exchange. HortScience 30, 1129-1131.

Blanke, M.M., 1991. Respiration of apple and avocado fruits. Postharvest News Info. 6, 429-436.

Brash, D.W., Charles, C.M., Wright, S., Bycroft, B.L., 1995. Shelf-life of stored asparagus is strongly related to postharvest respiratory activity. Postharvest Biol. Technol. 5, 77-81.

Burdon, J., Lallu, N., Wiklund, C., McLeod, D., Davy, M., 1999. Discrimination and prediction of softening in Hayward kiwifruit. Acta Hortic. 498, 217-224.

Eaks, I.L., 1976. Ripening, chilling injury, and respiratory response of 'Hass' and 'Fuerte' avocado fruits at $20{ }^{\circ} \mathrm{C}$ following chilling. J. Am. Soc. Hort. Sci. 101, 538-540.

Eaks, I.L., 1978. Ripening, respiration, and ethylene production of 'Hass' avocado fruits at $20-40{ }^{\circ} \mathrm{C}$. J. Am. Soc. Hort. Sci. 103, 576-578.

Eaks, I.L., 1980. Respiratory rate, ethylene production, and ripening response of avocado fruit to ethylene or propylene following harvest at different maturities. J. Am. Soc. Hort. Sci. 105, 744-747.

Eaks, I.L., 1983. Effects of chilling on respiration and ethylene production of 'Hass' avocado fruit at $20{ }^{\circ} \mathrm{C}$. HortScience $18,235-237$. 
Faubian, D.F., Mitchell, F.G., Mayer, G., 1992. Response of 'Hass' avocado to postharvest storage in controlled atmosphere conditions. Proceedings of Second World Avocado Congress, pp. 467-472.

Hertog, M.L.A.T.M., 2002. The impact of biological variation on postharvest population dynamics. Postharvest Biol. Technol. 26, 253-263.

Hertog, M.L.A.T.M., Peppelenbos, H.W., Evelo, R.G., Tijskens, L.M.M., 1998. A dynamic and generic model of gas exchange of respiring produce: the effects of oxygen, carbon dioxide and temperature. Postharvest Biol. Technol. 14, 335-349.

Hertog, M.L.A.T.M., Boerrigter, H.A.M., van den Boogaard, G.J.P.M., Tijskens, L.M.M., van Schaik, A.C.R., 1999. Predicting keeping quality of strawberries (cv. 'Elsanta') packed under modified atmospheres: an integrated model approach. Postharvest Biol. Technol. 15, 1-12.

Hertog, M.L.A.T.M., Nicholson, S.E., Banks, N.H., 2001. The effect of modified atmospheres on the rate of firmness change in 'Braeburn' apples. Postharvest Biol. Technol. 23, $175-184$.

Inoue, H., Tateishi, A., 2000. The application of non-destructive handy hardness meter for assessment of avocado fruit firmness. Acta Hortic. 517, 413-416.

Johnston, J.W., Banks, N.H., 1998. Selection of a surface coating and optimisation of its concentration for use on 'Hass' avocado (Persea americana Mill.) fruit. New Zealand J. Crop Hortic. Sci. 26, 143-151.

Kader, A.A., Zagory, D., Kerbel, E.L., 1989. Modified atmosphere packaging of fruits and vegetables. Crit. Rev. Food Sci. Nutr. 28, 1-30.

Kanellis, A.K., Loulakakis, K.A., Hassan, M.M., RoubelakisAngelakis, K.A., 1993. Biochemical and molecular aspects of low oxygen action on fruit ripening. In: Pech, J.C., Latché, A., Balagué, C. (Eds.), Proceedings of the International Symposium on Cellular and Molecular Aspects of Biosynthesis and Action of Plant Hormone Ethylene, 31 August-4 September 1992, Agen, France. Kluwer Academic Publisher, Dordrecht, the Netherlands, pp. 117-122.

Lambers, H., 1982. Cyanide-resistant respiration: a non-phosphorylating electron transport pathway acting as energy overflow. Physiol. Plant. 55, 478-485.

Lange, D.L., Kader, A.A., 1997a. Effects of elevated carbon dioxide on key mitochondrial respiratory enzymes in 'Hass' avocado fruit and fruit disks. J. Am. Soc. Hort. Sci. 122, $238-244$.

Lange, D.L., Kader, A.A., 1997b. Changes in alternative pathway and mitochondrial respiration in avocado in response to elevated carbon dioxide levels. J. Am. Soc. Hort. Sci. 122, 245-252.

Lange, D.L., Kader, A.A., 1997c. Elevated carbon dioxide exposure alters intracellular $\mathrm{pH}$ and energy charge in avocado fruit tissue. J. Am. Soc. Hort. Sci. 122, 253-257.

Maguire, K.M., Banks, N.H., Opara, L.U., 2001. Factors affecting weight loss of apples. Hort. Rev. 25, 197-234.

Meir, S., Akerman, Y., Fuchs, M., Zauberman, G., 1995. Further studies on the controlled atmosphere storage of avocados. Postharvest Biol. Technol. 5, 323-330.

Meir, S., Naiman, D., Akerman, M., Hyman, J.Y., Zauberman, G., Fuchs, Y., 1997. Prolonged storage of 'Hass' avocado fruit using modified atmosphere packaging. Postharvest Biol. Technol. 12, 51-60.

Peppelenbos, H.W., Tijskens, L.M.M., van’t Leven, J., Wilkinson, E.C., 1996. Modelling oxidative and fermentative carbon dioxide production of fruit and vegetables. Postharvest Biol. Technol. 9, 283-295.

Pesis, E., Marinansky, R., Zauberman, G., Fuchs, Y., 1994. Prestorage low-oxygen atmosphere treatment reduces chilling injury symptoms in 'Fuerto' avocado fruit. HortScience 29, $1042-1046$.

Polderdijk, J.J., Boerrigter, H.A.M., Tijskens, L.M.M., 1995. Possibilities of the model on keeping quality of vegetable produce in controlled atmosphere and modified atmosphere applications. Proceedings of the 19th International Congress of Refrigeration, vol. II, pp. 318-323.

Solomos, T., Kanellis, A.K., 1997. Hypoxia and fruit ripening. In: Kanellis, A.K., et al. (Eds.), Biology and Biotechnology of the Plant Hormone Ethylene. Kluwer Academic Publisher, Dordrecht, the Netherlands, pp. 239-252.

Tijskens, L.M.M., 1996. A model on the respiration of vegetable produce during postharvest treatments. In: Fenwick, G.R., Hedley, C., Richards, R.L., Khokhar, S. (Eds.), Agri-Food Quality, an Interdisciplinary Approach. The Royal Society of Chemistry, Cambridge, UK, p. 1996.

Tijskens, L.M.M., Polderdijk, J.J., 1996. A generic model for keeping quality of vegetable produce during storage and distribution. Agricultural Systems 51, 431-452.

Yahia, E.M., 1993. Reponses of some tropical fruits to insecticidal atmospheres. Acta Hortic. 343, 371-376. 